\section{Estudo \\ CoDebate}

em Cestão

Planejamento
Revista Estudo \& Debate, Lajeado, v. 26, n. 4, 2019. ISSN 1983-036X

DOI: http://dx.doi.org/10.22410/issn.1983-036X.v26i4a2019.2258

\title{
TRANSFERÊNCIAS CONSTITUCIONAIS E ARRECADAÇÃO PÚBLICA: ANÁLISE COMPARATIVA DO FPM NOS MUNICÍPIOS DO RIO GRANDE DO SUL ENTRE 2009 E $2016^{1}$
}

\author{
Mateus Machado de Pereira ${ }^{2}$, Reisoli Bender Filho ${ }^{3}$, Samuel Astolfi de Matos ${ }^{4}$, \\ Giulia Xisto 5
}

\begin{abstract}
Resumo: A fim de avaliar o nível de dependência dos 100 maiores e 100 menores municípios do Rio Grande do Sul em relação às transferências do Fundo de Participação dos Municípios (FPM), utilizou-se a análise da relação entre a Receita Orçamentária (RO) e o repasse estabelecido constitucionalmente para o FPM. Os resultados permitiram observar que os maiores municípios têm dependência de 15,19\% do FPM na composiçáo de suas receitas, percentual consideravelmente mais baixo que o encontrado para os menores municípios, $46,31 \%$. Ademais, constatou-se que a participaçáo do FPM em relação à receita total diminui conforme a população aumenta, sendo essa tendência de redução do grau de dependência do FPM maior em 2016 comparativamente a 2009. Nota-se também que a estrutura arrecadatória e a composição setorial econômica municipal são fatores que contribuem para explicar os níveis de dependência dos municípios.
\end{abstract}

Palavras-chave: Finanças municipais; Dependência fiscal; Arrecadação tributária.

1 Esse trabalho foi financiado pela Fundação de Amparo à Pesquisa do Estado do Rio Grande do Sul (FAPERGS).

2 Graduando de ciências econômicas, atua como bolsista PROBIC.

3 Professor adjunto da Universidade Federal de Santa Maria. Atualmente é bolsista de produtividade do Conselho Nacional de Desenvolvimento Científico e Tecnológico (CNPq), editor associado da Revista Práticas de Administração Pública e coordenador da Universidade Aberta do Brasil na UFSM. Tem experiência na área de Economia, com ênfase em Economia, Macroeconomia e Finanças Públicas, atuando principalmente nos seguintes temas: economia brasileira, competitividade, comércio internacional, acordos comerciais, macroeconomia e endividamento público.

4 Graduando em Ciência Econômicas.

5 Graduanda em Administração. 


\title{
CONSTITUTIONAL TRANSFER AND PUBLIC COLLECTION: ANALYSIS OF FPM IN THE MUNICIPALITIES OF RIO GRANDE DO SUL
}

\begin{abstract}
In order to evaluate the level of dependence of the 100 largest and 100 smallest municipalities of Rio Grande do Sul in relation to the transfers of the Municipal Participation Fund (FPM), the relation between the Budgetary Revenue (BR) of each municipality and the transfer constitutionally instituted by the federal government for the MPF has been analyzed. The results showed that the largest municipalities have a dependence of $15.19 \%$ of the MPF in the composition of their revenues, a percentage considerably lower than that found for the smaller municipalities, $46.31 \%$. In addition, it was verified that the participation of the FPM in relation to the total revenue decreases as the population increases, being this tendency of reduction of the degree of dependence of the MPF greater in 2016 compared to 2009. It is also noted that the collection structure and the municipal economic sector composition are factors that contribute to explain the levels of dependence of municipalities.
\end{abstract}

Keywords: Municipal Finance, Tax dependency; Tax collection.

\section{Introdução}

A elevada heterogeneidade demográfica e estrutural entre os municípios brasileiros tem consolidado as crescentes disparidades sociais, econômicas e produtivas entre estes entes públicos, característica que torna necessário um sistema de equalização das disparidades regionais, para Cossio (2002) este sistema está amparado em instrumentos constitucionais que garantem aos municípios uma parcela da totalidade dos recursos arrecadados pela União, caso do Fundo de Participação dos Municípios (FPM).

Nestes termos, a divisão da receita proveniente da arrecadação tributária representa um mecanismo fundamental para amenizar as desigualdades regionais na busca da manutençáo do equilíbrio socioeconômico entre os governos de diferentes níveis, especificamente os municípios (MARQUES JÚNIOR, OLIVEIRA E LAGEMMAN, 2012). Para esses últimos, os repasses do FPM representam, senáo a principal fonte de recursos de grande parte dos municípios, o montante necessário para equilibrar o orçamento fiscal.

Santos e Santos (2014) discutem que o federalismo fiscal tem caráter descentralizador administrativo, social e financeiro para os estados e municípios; além disso, promove uma transferência intergovernamental, com base na composição populacional. Giroldo e Kempfer (2012) complementam, enfatizando que o federalismo fiscal está ligado ao federalismo cooperativo, orçamento público, competências materiais e recursos para cumpri-las, consistentes em sua própria capacidade tributária e transferências financeiras, culminando na própria autonomia dos entes públicos.

Entretanto, as recorrentes crises econômicas que vêm acompanhadas de encolhimento da atividade produtiva em todos os níveis têm produzido efeitos duplamente negativos na estrutura financeira dos municípios FAMURS (2016). Se, de um lado, as receitas próprias reduzem-se pelo efeito direto da baixa capacidade de expansão econômica; por outro, as transferências fiscais da União aos municípios retraem-se pela baixa arrecadação tributária resultante destas instabilidades econômico-políticas. 
Esta conjuntura tem exposto limites ao equilíbrio fiscal dos municípios, principalmente daqueles definidos como de pequeno porte. No mais, tem elevado o nível de dependência destes entes de recursos de outras esferas públicas, em específico do FPM, transferência que se constitui na principal fonte de recursos de cerca de $81 \%$ dos municípios brasileiros, conforme exposto por BREMAEKER (2011).

Nesta mesmalinha, Massardi e Abrantes (2016) indicam para uma elevada dependência dos municípios pequenos ao analisar a dependência do FPM para os municípios mineiros, enquanto Santos e Santos (2008) chegaram a resultados similares analisando a dependência dos municípios do estado da Bahia.

No Rio Grande do Sul, estado em que os municípios considerados de pequeno porte ${ }^{6}$ ultrapassam os $90 \%$, este processo não tem sido diferente, dado que esses entes públicos têm enfrentado crescentes e agravados problemas fiscais. A partir destas discussóes, avaliar o grau de dependência orçamentária dos municípios do estado do Rio Grande do Sul em relação às transferências do Fundo de Participação dos Municípios torna-se relevante ao entendimento da dinâmica da estrutura fiscal, especialmente em períodos de instabilidades e de retração da atividade econômica.

Nesta perspectiva, para Costa e Castelar (2015) a gestão financeira municipal ainda é um tema pouco explorado e considerando que expansão das despesas públicas pode resultar em desequilíbrios, assim as finanças municipais precisam ser fiscalizadas, de forma que recursos públicos sejam melhor alocados, por isso, justificam-se análises por unidades federativas. De forma complementar, analisaram-se os resultados comparativamente a estrutura econômica e tributária dos municípios, buscando explicaçóes para caracterizar os municípios em relação ao nível de dependência dos repasses do FPM.

Como característica geral da estrutura orçamentária brasileira, os municipíos de grande porte possuem maior capacidade de arrecadar as receitas próprias. Já os municípios de médio porte dependem mais detidamente de impostos sobre circulação de mercadorias e serviços, enquanto que os pequenos municípios dependem quase que integralmente das transferências constitucionais, com destaque para o Fundo de Participação dos Municípios (FPM).

Embora representem cerca de 85\% dos municípios do país (CNM, 2017), estudos acerca da estrutura fiscal dos pequenos municípios, com destaque aos recursos de transferências, ainda encontram vasto campo de análise. De tal modo, além do debate acerca do equilíbrio fiscal, o estudo também busca incentivar discussões a respeito de alternativas de arrecadação própria dos municípios do Rio Grande do Sul.

Além desta seção preambular, o artigo está dividido em outras quatro seções. A segunda traz arcabouço sobre a estrutura das receitas fiscais e o Fundo de Participação dos Municípios. Na terceira apresentam-se os procedimentos metodológicos e descritos

6 Aqueles com populaçáo abaixo de 50.000 habitantes, classificam-se em municípios de pequeno porte 1 , com população até 20.000 habitantes e os de pequeno porte 2, com população entre 20.001 e 50.000 habitantes; entre 50.001 e 100.000 habitantes são denominados de médio porte; entre 100.001 e 900.000 habitantes grande porte e; acima de 900.000, metrópole (IBGE, 2010). 
dados utilizados. E nas duas seções seguintes, são discutidos os resultados e delineadas das conclusóes.

\section{Fundamentação teórica}

\subsection{Repartição de receita}

A Constituição Federal de 1988 repartiu as competências tributárias de modo que cada ente possua sua competência privativa e exclusiva, vedando bitributação. Em todas as federações a arrecadação é maior no nível mais amplo e menor nos níveis locais, tornando necessária a transferência de recursos da instância central aos governos subnacionais (REZENDE, 2006).

Esta transferência, de longa data, faz parte da estrutura orçamentária pública brasileira. Ela foi instituída na Constituição Federal de 1964, sendo formada inicialmente por 10\% do produto da arrecadação dos impostos sobre renda (IR) e sobre produtos industrializados (IPI). Posteriormente foi regulamentado pelo Código Tributário Nacional (CTN - Lei n. ${ }^{\circ}$ 5.172, de 25 de outubro de 1966), no seu artigo 91, tendo sua distribuição iniciada em 1967. Mais tarde, a Constituiçáo Federal de 1988 ratificou e ampliou gradativamente o percentual de participação do FPM no IR e IPI até o valor de 22,5\% a partir de 1993.

Estas transferências, além de corrigir as diferenças entre atribuiçóes e receitas nos diferentes níveis de governo (ou o desequilíbrio vertical na federação), representam uma oportunidade de atenuar as disparidades regionais. Baiao (2013) salienta ainda que o território de um país raramente é homogêneo do ponto de vista econômico e social.

Conforme expresso no Manual da Receita Nacional (2008), as transferências intergovernamentais compreendem a entrega de recursos, correntes ou de capital, de um ente a outro. É importante destacar que essas transferências ocorrem entre esferas distintas de governo, não guardando relação com as operações intraorçamentárias.

No art. 158, a CF/1988 estabelece que pertencem aos municípios: o produto da arrecadaçáo do imposto da Uniáo sobre renda e proventos de qualquer natureza, $50 \%$ do produto da arrecadação do imposto da Uniáo sobre a propriedade territorial rural, $50 \%$ do produto da arrecadação do imposto do estado sobre a propriedade de veículos automotores e $50 \%$ do produto da arrecadação do imposto do estado sobre operaçóes relativas à circulação de mercadorias e sobre prestaçóes de serviços de transporte interestadual e intermunicipal e de comunicação (BRASIL, 2013).

No Brasil, devido à desigualdade regional e a grande heterogeneidade e extensão de seu território, as transferências aos governos subnacionais tornam-se ainda mais importantes. Conforme destaca Rezende (2006), um dos desafios do federalismo fiscal tem sido enfrentar a ampliação das disparidades regionais, que concentram as bases tributárias em pontos específicos do território e, consequentemente, afetam a repartição das receitas tributárias entre os entes federativos.

Assim, todas as federaçóes ainda centralizam em algum grau sua arrecadação tributária, apesar da tendência de descentralização verificada em diversos países nas últimas 
décadas (ABRÚCIO, 2005). Conforme destaca Prado (2007), na totalidade de federaçóes mundiais, os governos dos níveis superiores arrecadam mais do que gastam, enquanto os de níveis inferiores gastam mais do que arrecadam, recebendo assim o nome de brecha vertical. Isso explica porque todas as federaçôes fazem uso de transferências verticais.

Logo, analisando verticalmente a estrutura tributária dos entes da federação, a União arrecada e aplica seus impostos, que são formadores de recursos para repasses aos estados e municípios. Detalhadamente, no Quadro 1, encontra-se a divisão das receitas da União, estados e municípios, organizados entre receitas próprias e receitas de transferência, sendo discorridas as suas peculiaridades no rateio, conforme lei específica, por meio de índices para a distribuição dos respectivos valores.

Quadro 1 - Repartição da receita por esfera de governo

\begin{tabular}{|c|c|c|}
\hline UNIÂO & ESTADOS & MUNICIPIOS \\
\hline Receitas Próprias & Receitas Próprias & Receitas Próprias \\
\hline Imposto sobre importação - II & $\begin{array}{l}\text { Imposto de transmissáo causa mortis } \\
\text { e doaçáo-ITCMD }\end{array}$ & $\begin{array}{l}\text { Imposto Predial e Territorial Urbano } \\
\text { - IPTU }\end{array}$ \\
\hline Imposto sobre Exportação - IE & $\begin{array}{l}\text { Imposto sobre Operaçóes relativas } \\
\text { à Circulaçáo de Mercadorias e } \\
\text { Prestação de Serviços de Transporte } \\
\text { Interestadual e Intermunicipal e de } \\
\text { Comunicaçáo - ICMS } \\
\end{array}$ & $\begin{array}{l}\text { O Imposto de Transmissão de Bens } \\
\text { Imóveis Inter Vivos - ITBI }\end{array}$ \\
\hline Rendas e Proventos & \begin{tabular}{|l|l|}
$\begin{array}{l}\text { Imposto sobre propriedade de } \\
\text { veículos automotores - IPVA }\end{array}$ \\
\end{tabular} & $\begin{array}{l}\text { Imposto Sobre Serviços de Qualquer } \\
\text { Natureza - ISS } \\
\end{array}$ \\
\hline $\begin{array}{llr}\text { Imposto sobre } & \text { produtos } \\
\text { industrializados } & - & \text { IPI } \\
\text { (Exportaçá) } & & \\
\end{array}$ & $\begin{array}{l}\text { Imposto de Renda Retido na Fonte } \\
\text { - IRRF }\end{array}$ & $\begin{array}{l}\text { Imposto de Renda Retido na Fonte } \\
\text { - IRRF }\end{array}$ \\
\hline \multicolumn{3}{|l|}{ Operaçôes crédito, câmbio... } \\
\hline & Receitas de transferências & Receitas de transferências \\
\hline Imposto Territorial Rural - ITR & 20\% Imposto Extraordinário & $\begin{array}{l}50 \% \text { ou } 100 \% \text { Imposto Territorial } \\
\text { Rural - ITR }\end{array}$ \\
\hline Grandes Fortunas & $\begin{array}{l}\text { 21,5\% Fundo de Participaçáo dos } \\
\text { Estados - FPE }\end{array}$ & $\begin{array}{l}50 \% \text { Imposto sobre propriedade de } \\
\text { veículos automotores - IPVA }\end{array}$ \\
\hline Extraordinários (novos) & $\begin{array}{l}10 \% \text { Imposto sobre produtos } \\
\text { industrializados - IPI (Exportaçáo) }\end{array}$ & $\begin{array}{l}25 \% \text { Imposto sobre Operaçóes } \\
\text { relativas à Circulaçáo de Mercadorias } \\
\text { e Prestação de Serviços de Transporte } \\
\text { Interestadual e Intermunicipal e de } \\
\text { Comunicação - ICMS }\end{array}$ \\
\hline CIDE Combustível & 29\% CIDE Combustível & $\begin{array}{l}\text { 23,5\% Fundo de Participação dos } \\
\text { Municípios - FPM } \\
\end{array}$ \\
\hline \multirow[t]{2}{*}{ Outras Contribuiçôes } & & \begin{tabular}{|l}
$25 \%$ Imposto sobre produtos \\
industrializados - IPI (Exportação)
\end{tabular} \\
\hline & & 25\% CIDE Combustível \\
\hline
\end{tabular}

Fonte: Adaptado pelos autores com base CTN e Marcuzzo, 2013.

A repartição de receitas está estabelecida conforme a Constituição Federal, o Código Tributário e as Leis Complementares, em que cada tributo partilhado segue uma regra específica. Verifica-se que o Fundo de participação dos Municípios (FPM) é arrecadado 
pela União, formado pelo Imposto sobre a Renda e Proventos de Qualquer Natureza (IR) e o Imposto sobre Produtos Industrializados (IPI) e é partilhado de acordo com a faixa populacional e a renda per capita, conforme Decreto-Lei n. ${ }^{0}$ 1.881. Igualmente ocorre com o Imposto de Circulação de Mercadorias e Serviços (ICMS), cujo estado arrecadador partilha $50 \%$ com os municípios conforme coeficiente de distribuição específico e também com o Imposto sobre Veículos Automotores (IPVA), arrecadado pelo estado e partilhado $50 \%$ com os municípios onde os veículos são emplacados.

Ainda, destaca-se que, conforme Instrução Normativa (IN) da Receita Federal do Brasil n. ${ }^{\circ}$ 643, de 12 de abril de 2006, os municípios podem celebrar convênio com a Secretaria da Receita Federal (SRF), dessa forma sendo beneficiados com $100 \%$ do valor de arrecadação do Imposto Territorial Rural (ITR); entretanto, passam a ser responsáveis por todo o processo de fiscalização do tributo.

A municipalização do ITR é uma oportunidade de aumentar as receitas, sendo que a Constituiçáo Federal prevê que seja dividido entre a União e os municípios a parcela arrecadada. A partir da Instrução Normativa n. ${ }^{\circ} 884$, de 06 de no*vembro de 2008, foram definidos todos os requisitos e condiçóes necessárias para celebração do referido convênio. A partir deste momento, ocorreu adesão de grande parte dos municípios, os quais passaram a receber $100 \%$ do valor arrecadado.

\subsection{Fundo de Participaçáo dos Municípios}

Os municípios com suas despesas estatais e necessidades de investimento precisam de fontes de renda para os devidos custeios. Tais custeios se dão por meio das receitas tributárias que podem provir de contribuiçóes de melhoria, impostos, taxas, empréstimos compulsórios e outras contribuiçôes, sendo todos prefixados em lei de caráter permanente.

Entretanto, entre os anos de 1964-1967, com a estruturação do sistema tributário, os municípios tiveram reduzida sua capacidade de legislar sobre questôes tributárias, de forma que ocorreu a centralização de impostos pela União. Com isso, a União passou a ter poder de decisão nos incentivos fiscais e os municípios passaram a ter o poder de decisão de apenas dois impostos: o ISSQN - Imposto sobre Serviços de Qualquer Natureza e o IPTU - Imposto Predial e Territorial Urbano (THEÓPHILO et al., 2011).

No entanto, a partir disso foi necessário pensar em formas de transferência aos municípios a fim de reduzir as disparidades de renda e, portanto, foi criado o Fundo de Participação dos Municípios (FPM). Em seu ano de criação (1965) as transferências do FPM eram compostas de $10 \%$ do Imposto de Renda e do Imposto sobre Produtos Industrializados menos as reduçóes, deduçôes e incentivos fiscais da época. A partir de 1966 surgiu o Código Tributário Nacional que pôde regulamentar o FPM, mas sua distribuição só ocorreu um ano depois (SANTOS e SANTOS, 2014).

Além disso, a Lei n. 5.172 de 1966 instituiu a distribuição do FPM em 10\% para os municípios das capitais dos estados e $90 \%$ para os demais municípios do país, sendo que cada município recebe as transferências de acordo com seu fator representativo populacional (BRASIL, 1966). Atualmente, do montante de recursos repassados, 86\% destinam-se para os municípios do interior; 3,6\% para os municípios da reserva e; $10 \%$ para as capitais. 
Para efeitos de classificação, as capitais são Brasília e as capitais estaduais; os municípios da reserva são aqueles com população a partir de 142.633 habitantes; e os do interior são os demais municípios.

Mais tarde, a Constituição Federal de 1988 ratificou o FPM (Art. 159, inciso I, alínea "b" e ADCT art. 34, $\$ 2^{\circ}$, incisos I e III) e recepcionou a regulamentação do CTN, tendo ainda aumentado gradativamente o percentual de participação do FPM no IR e IPI dos $17 \%$ até o valor de 22,5\% a partir de 1993 e solicitado, em seu artigo 161, inciso II, que Lei Complementar regulamentasse a entrega dos recursos do Fundo.

Recentemente, em 2007, ocorreu alteração a partir da Emenda Constitucional n. ${ }^{\circ}$ 55 , que acrescentou a alínea " $\mathrm{d}$ " ao art. 159 , inciso I, adicionando $1 \%$ ao percentual do FPM (que assim passou a ter alíquota de 23,5\%). Este percentual a mais, entretanto, seria acumulado na Conta Única do Tesouro Nacional ao longo de 12 meses, para ser entregue aos municípios por seu valor integral no $1^{\circ}$ decêndio de dezembro de cada ano.

A repartição do Fundo de Participação dos Municípios atende aos fatores populacional e de renda per capita do estado. Para o primeiro, o valor da cota parte individual aumenta conforme a população do município, enquanto que para o segundo, a relação é inversamente proporcional, quanto maior a renda per capita menor o coeficiente, sendo calculado a partir da renda per capita do estado e do Brasil. Ainda, embora à distribuição sejam considerados aos mesmos fatores, cada tipo qualificado de município (interior, reserva e capital) possui coeficientes e bases de cálculo distintas (MENDES, 2015).

\section{Metodologia}

Com o objetivo de avaliar o nível de dependência dos municípios do Rio Grande do Sul em relação às transferências do Fundo de Participação dos Municípios (FPM), utilizouse para a análise a relação entre a Receita Orçamentária $(\mathrm{RO})$ de cada município e o repasse estabelecido constitucionalmente pelo Governo Federal para o FPM. A partir disso, se torna possível avaliar a proporção ou relevância do FPM nas receitas orçamentárias, metodologia já foi utilizada por Santos e Santos (2014) e Massardi e Abrantes (2016) para evidenciar o nível de dependência dos municípios. A relação proposta encontra-se formalizada nas equaçóes em (1) e em (2), respectivamente.

$$
\text { Dependência }=\frac{\text { FPM }}{\text { RO }}
$$

$$
\% \text { Dependência }=\frac{\text { Dependência }}{100}
$$

Estas relações demonstram a participação do FPM à formação das receitas orçamentárias dos municípios do Rio Grande do Sul. Para tanto, o estado foi dividido em duas amostras: uma compreendeu os 100 menores e a outra os 100 maiores em contingente populacional, para os anos de 2009 e 2016, doravante denominado grupo I e grupo II. Esta amostra compreende $40 \%$ dos municípios do estado; quando estratificada, divide-se 
em $50 \%$ dos municípios de pequeno porte $1,29 \%$ dos de pequeno porte $2,12 \%$ de médio porte, $10 \%$ de grande porte e $1 \%$ metrópole, conforme classificação do IBGE (2010).

As informaçóes utilizadas referentes a Receita Orçamentária foram coletadas no sítio do Tribunal de Contas do Estado do Rio Grande do Sul e os valores do Fundo de Participação dos Municípios no sítio do Tesouro Nacional. Ressalta-se que as Receitas Orçamentárias foram contabilizadas com as deduçóes contábeis, como deduçóes de impostos e taxas.

A amostra escolhida, composta dos menores e dos maiores, teve o intuito de analisar como o tamanho populacional influencia no nível de dependência dos municípios em relação ao FPM, bem como implica no entendimento da situação fiscal dos diferentes entes municipais. O estado do Rio Grande do Sul, por apresentar municípios com elevada heterogeneidade geográfica e econômica, possui estruturas arrecadatórias diametralmente diferenciadas. Especificamente, a análise seguiu três etapas para os dois conjuntos de municípios (grupos I e II), quais sejam: (i) análise comparativa do nível de dependência do FPM entre os anos de 2009 e 2016 e (ii) avaliação detalhada dos dez municípios mais e menos dependentes do FPM.

Complementando, em uma terceira etapa, com o objetivo de compreender a formação da estrutura orçamentária dos municípios, avaliaram-se as diversas fontes de receita (FR), leia-se receitas tributárias e de transferências, para as quais foram mensuradas a proporção destes recursos em relação ao total das Receitas Correntes (RC) nos dez municípios mais e menos dependentes em cada grupo analisado, para o ano de 2016, método semelhante ao utilizado por Brito (2016).

Ainda, foi mensurado o peso de cada setor da economia (agropecuário, industrial e de serviços) na formação do Valor Adicionado Bruto nominal (VAB) com o intuito de avaliar a relação entre setores estratégicos e a dependência dos municípios das transferências constitucionais. As informaçóes para esta análise correspondem ao ano de 2015 (os dados para 2016 e 2009 não estão disponíveis) e foram coletadas junto a Fundação de Economia e Estatística (FEE).

\section{Resultados e discussão}

\subsection{Dependência do FPM - municípios menores (grupo I)}

Considerando a estrutura demográfica e fiscal, analisou-se em uma primeira etapa o nível de dependência do FPM dos 100 menores municípios do Rio Grande do Sul (grupo I), nos anos de 2009 e de 2016. Esses dois anos apresentaram características econômicopolíticas bastante distintas; enquanto que, no primeiro, a atividade econômica refletia os efeitos da crise econômica internacional, já no segundo, a conjuntura foi marcada pelo desequilíbrio fiscal e pela instabilidade política. Este conjunto de municípios encontra-se na menor faixa populacional, entre 1.243 e 2.735 habitantes, apresentando coeficiente de FPM de 0,6, utilizado como referência para os menores municípios.

A participação relativa do FPM nas receitas orçamentárias dos municípios analisados, para ambos os anos, está detalhada na Figura 1. Dos resultados, quatro evidências podem ser destacadas: (i) a participação do Fundo de Participação dos Municípios em relação a 
receita total reduz conforme a população aumenta; (ii) a tendência de reduçáo do grau de dependência do FPM foi maior em 2016 comparativamente ao ano de 2009; (iii) a participaçáo média do FPM ficou em 47\%, sendo que essa participaçáo retraiu de 47,9\% em 2009 para 46,1\% em 2016 e; (iv) o intervalo entre os mais e menos dependentes ficou entre $60 \%$ e $30 \%$.

A partir de Massardi e Abrantes (2016), que definem valores acima de 50\% como alto o nível de dependência, a participação do FPM nas receitas orçamentárias dos municípios gaúchos é elevada, dado que indica que, para alguns municípios, mais da metade das receitas são provenientes de transferências, isso torna o ente local suscetível à volatilidade nas receitas originárias de outras esferas públicas.

Figura 1 - Participação do FPM na receita orçamentária dos 100 menores municípios do Rio Grande do Sul em 2009 (painel a) e 2016 (painel b), em \%.

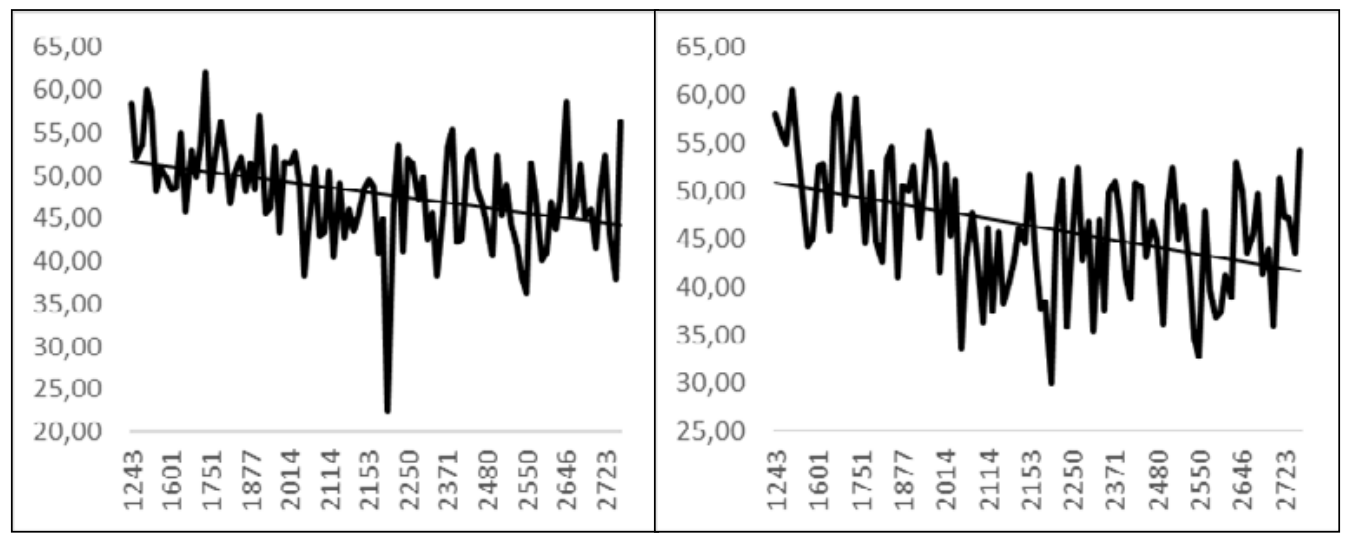

(a)

(b)

Fonte: Elaborado pelos autores.

A segunda etapa consistiu na identificação dos municípios menos e mais dependentes entre aqueles considerados de pequeno porte (grupo I). Os resultados encontram-se na Figura 2. Em relação aos dez municípios menos dependentes verifica-se que ocorreram pequenas mudanças entre os anos analisados, ficando entre $55 \%$ e $62 \%$ em 2009 e, entre $54,5 \%$ e 60,5\%, em 2016; assim, apesar das mudanças políticas, a diferença entre os anos não se mostra expressiva. Por outro lado, entre os dez municípios mais dependentes, a dispersão foi ainda menor, permanecendo entre $36 \%$ e $41 \%$ em 2009 e $33 \%$ e $37 \%$ em 2016.

A exceção destes resultados ficou a cargo de Pinhal da Serra, que apresentou níveis de dependência inferiores ao padrão destes municípios, cuja participação do FPM na receita orçamentária ficou em $22 \%$ e $30 \%$, em ambos os anos. Vale ressaltar que o município Pinhal da Serra tem um a segunda maior renda per capita do Rio Grande do Sul (FEE, 2015), assim como uma arrecadação per capita classificada entre as melhores do Brasil e do Rio Grande do Sul, devido a recursos provenientes de impostos e da geraçáo da energia (PINHAL DA SERRA, 2019). 
Figura 2 - Participação do FPM na receita orçamentária dos 10 municípios mais e menos dependentes do Rio Grande do Sul em 2009 (painel a) e 2016 (painel b), em \%.

\begin{tabular}{|c|c|c|c|}
\hline LINHA NOVA & 62,10 & CARLOS GOMES & 6062 \\
\hline CARLOS GOMES & 60.13 & SANTA TEREZA & 60,06 \\
\hline ITATI & 58,66 & LINHA NOVA & 59,75 \\
\hline ANDRÉ DA ROCHA & 58,45 & ANDRÉ DAROCHA & 5798 \\
\hline TUPANCI DO SUL & 57.46 & GUABIJU & 5789 \\
\hline MULITERNO & 57.10 & NOVOXINGU & 56,18 \\
\hline LAGOA BONITA DO SUL & 56.42 & UNIÃO DA SERRA & 56.13 \\
\hline CANUDOS DO VAIE & $56 \times 35$ & TUPANCI DO SUL & 55.27 \\
\hline BENJAMIN CONSTANT... & 55,45 & COQUEIRO BAIXO & 54.94 \\
\hline PORTO VERA CRUZ & 55,09 & SÃO PEDRO DAS MISSÕES & 54.67 \\
\hline SANTO ANTÔNIO DO... & 4096 & FAGUNDES VARELA & 36,88 \\
\hline BOA VISTA DO CADEADO & 40.72 & VILA LÂNGARO & $36 \times 36$ \\
\hline NOVA BOA VISTA & 40,48 & BOA VISTA DO CADEADO & 36,12 \\
\hline FAGUNDES VARELA & 40.14 & QUEVEDOS & 35.98 \\
\hline COQUEIROS DO SUL & 38,37 & SÃO VENDELINO & 35,79 \\
\hline PEDRAS ALTAS & 38,32 & SÃO IOSÉ DO INHACORÁ & 35,35 \\
\hline BARRA FUNDA & 38,14 & BARRA FUNDA & 34.76 \\
\hline CAMARGO & 3795 & PEDRAS ALTAS & 33,54 \\
\hline MARATA & 36,24 & MARATÁ & 32,82 \\
\hline PINHAL DA SERRA & 22,37 & PINHAL DA SERRA & Bomo1 \\
\hline
\end{tabular}

(a)

(b)

Fonte: Elaborado pelos autores.

Os resultados demostraram que os municípios de Maratá, Camargo, Barra Funda, Boa Vista do Cadeado e Fagundes Farela mantiveram-se entre os dez menos dependentes do FPM nos dois períodos analisados. Quando se relaciona o grau de dependência destes repasses com a população, observa-se que, em 2009, os menos dependentes estavam na faixa populacional acima de 2.000 habitantes, enquanto que os mais dependentes, exceto Benjamin Constant do Sul, Lagoa Bonita do Sul e Itati, encontravam-se abaixo deste limite populacional. Esta situação fragmentou-se em 2016, quando os menores e os maiores níveis de dependência do FPM foram totalmente divididos pela população limite de 2.000 habitantes.

Por outro lado, entre os mais dependentes, somente dois municípios figuraram nos anos de 2009 e 2016, André da Rocha e Carlos Gomes. Este resultado demonstra uma tendência de ampliação dos níveis de dependência de recursos de transferências, ratificando o exposto por Bremaeker (2011), de que pequenas variaçóes nos repasses tendem a provocar importantes alteraçóes na estrutura orçamentária dos menores municípios. Igualmente, destaca-se a conjuntura adversa dos últimos três anos, ocasionada pelo aprofundamento das crises fiscal e política, que impactou mais fortemente nas transferências da União e, por sua vez, nos orçamentos municipais.

Nesta linha, conforme exposto pela Federação das Associações de Municípios do Rio Grande do Sul (2017), com a recessão econômica, a alta do desemprego e a redução do 
rendimento real das pessoas ocupadas, as receitas públicas sofreram queda brusca. Em 2015 e 2016, a perspectiva do valor de transferência do FPM foi reduzida, conforme previsto nas Leis Orçamentárias, não se concretizou, resultando em retração de mais de $\mathrm{R} \$ 777$ milhóes nos repasses para os municípios do Rio Grande do Sul, o valor previsto era de $\mathrm{R} \$ 6,2$ bilhóes FAMURS (2015).

Constantino (2015) discute sobre os critérios da repartição de recursos do FPM, e conclui que o FPM para os municípios do interior é distorcido, pois seus critérios de distribuição são desatualizados (fixo desde 1989/1990), além de serem homogêneos no critério população, para municípios em condiçôes socioeconômicas diferentes, o que reduz a capacidade desse recurso ser distribuidor de renda. Ainda Constantino (2015) afirma que o FPM privilegia municípios muito pequenos em estados mais ricos, características do Rio Grande do Sul.

A partir deste cenário de incertezas, os municípios têm passado por inúmeros problemas pela falta de disponibilidade financeira para atender as demandas locais. Esta situação foi levemente amenizada no final do ano de 2016, a partir dos valores obtidos com o Programa de Regularizaçáo de Ativos no Exterior, conhecido como repatriação de recursos, que trouxe à economia brasileira $\mathrm{R} \$ 46,8$ bilhóes oriundos do IR e da multa de regularização. Deste montante, cerca de $11 \%$, equivalente a $\mathrm{R} \$ 5,26$ bilhôes, foi partilhado com os municípios.

\subsubsection{Estrutura arrecadatória e atividade econômica setorial}

Complementando, nesta terceira etapa, a composição fiscal e a divisão setorial da atividade econômica possibilitaram ampliar o entendimento da estrutura arrecadatória dos municípios do Rio Grande do Sul. Em relação ao primeiro aspecto, a Tabela 1 detalha as informaçóes sobre as fontes de receitas dos municípios menos e mais dependentes do grupo, onde fica destacada a dependência dos municípios das transferências governamentais. Além disso, observa-se a importância do ICMS que depende da circulação de mercadorias, mas tem um efeito ao diminuir o peso do FPM nas receitas de transferências.

Tabela 1 - Estrutura fiscal dos dez municípios mais de menos dependentes do FPM, do grupo I, para o ano de 2016

\begin{tabular}{lll}
\hline & Receita tributária municipal e seus componentes \\
\hline & Mais dependentes & Menos dependentes \\
\hline Receita tributária & $\mathbf{3 \%}$ & $\mathbf{4} \%$ \\
ISS & $24 \%$ & $21 \%$ \\
IPTU & $13 \%$ & $16 \%$ \\
ITBI & $16 \%$ & $22 \%$ \\
IRFF & $35 \%$ & $26 \%$ \\
Taxa e contribuiçóes de melhorias & $12 \%$ & $15 \%$ \\
\hline
\end{tabular}




\begin{tabular}{lll}
\hline & Receitas de transferências e seus principais componentes \\
\hline & Mais dependentes & Menos dependentes \\
\hline Transferências & $\mathbf{9 3} \%$ & $\mathbf{8 3} \%$ \\
FPM & $63 \%$ & $48 \%$ \\
ICMS & $20 \%$ & $31 \%$ \\
Outros & $17 \%$ & $21 \%$ \\
\hline
\end{tabular}

Fonte: Resultados da pesquisa. Elaborado pelos autores com dados do sistema Meu Município.

Ao analisar comparativamente, nota-se que os municípios mais dependentes possuem menor capacidade de arrecadar tributos próprios, especialmente aqueles oriundos da atividade econômica produtiva, indicando certa incapacidade estrutural em gerar receita, conforme destaca Ribeiro (2016) este fato é corroborado ao observar a divisão das receitas de transferência, onde, para os municípios menos dependentes, o Imposto sobre Circulação de Mercadorias e Serviços (ICMS) representa percentual consideravelmente maior do que o encontrado nos mais dependentes, por outro lado, o FPM consiste na principal fonte de transferência dos mais dependentes. Além disso, destaca-se a concentração dos recursos de transferências em reduzidos tributos, o que ocasiona em maior suscetibilidade dos orçamentos municipais a cenários econômicos adversos.

Complementando, a dinâmica da atividade econômica nesses municípios foi analisada a partir da divisão setorial da produção, considerando o Valor Adicionado Bruto Total (VAB) - setores agropecuário, industrial e de serviços (Tabela 2). Complementando, observa-se que a concentração da atividade econômica baseia-se no setor agropecuário, predominante nos municípios menores, impactando também na arrecadação própria, enquanto que a produção industrial representa a menor fonte de arrecadação setorial. Os dados para 2009 não estão disponíveis.

Tabela 2 - Participação setorial no Valor Adicionado Bruto dos municípios mais e menos dependentes do grupo I, para o ano de 2015, em valores médios.

\begin{tabular}{lll}
\hline & Mais dependentes & Menos dependentes \\
\hline Agropecuária & $53 \%$ & $39 \%$ \\
Indústria & $4 \%$ & $22 \%$ \\
Serviços & $43 \%$ & $38 \%$ \\
PIB em R \$ milhóes & 52 & 129 \\
\hline
\end{tabular}

Fonte: Resultados da pesquisa. Elaborada pelos autores com dados da Fundação de Economia e Estatística. Os dados para o ano de 2016 não estão disponíveis.

No grupo dos dez municípios mais dependentes, em média, apenas $4 \%$ do produto agregado em termos de VAB origina-se da indústria, mostrando que esse setor possui baixa capacidade de geração de valor econômico. Esta evidência elucida a desvantagem dos municípios menos industrializados encontrados por Santos e Santos (2008), já que sua receita proveniente de impostos relativos à produção industrial é menor, assim como a 
arrecadação de circulação de mercadorias também é menor, amplificando a dependência de transferências governamentais diretas.

Já os dez municípios menos dependentes do grupo I possuem atividade econômica mais diversificada, com a proporção média do Valor Adicionado Bruto distribuída de forma mais equilibrada entre os setores, com destaque para o VAB médio da indústria, que representa $22 \%$, muito superior ao dos municípios mais dependentes, também associando ao ICMS, esses municípios uma maior circulação de produtos, assim arrecadação proveniente de consumo é mais eficaz no grupo. Entretanto, como o porte desses municípios é pequeno, as transferências governamentais continuam essenciais, uma vez que o volume arrecadado de recursos próprios não é suficiente para alcançar o equilíbrio fiscal.

Outra diferença significativa entre os municípios do grupo I está na atividade econômica, com os menos dependentes com PIB médio aproximadamente 1,5 vez maior comparativamente aos mais dependentes de recursos do FPM (Figura 2). Faz-se oportuno relacionar essa diferença com o contingente populacional médio dos grupos, a qual corresponde a cerca 40\%, com os dez mais dependentes com população entre 1.350 e 1.900 habitantes e os dez menos dependentes a população variando entre 2.000 e 2.700 habitantes. De forma paralela, os menores municípios tendem a apresentar estrutura econômica com baixa agregação de valor, baseada em produção primária, e menor capacidade tributária.

Estas evidências corroboram os resultados para o estado como um todo, dado que as receitas próprias representam pequena parcela dos recursos orçamentários, enquanto que os recursos de transferências são predominantes na composição orçamentária. Em 2016, para os dez municípios mais e menos dependentes, essa fonte de recursos representou, em média, 3,5\% do total das receitas correntes, enquanto que as receitas de transferências do FPM representaram 55,5\% do total. Ressalta-se que, no Rio Grande do Sul, cerca de 90\% do total de 497 municípios enquadram-se na categoria de pequenos municípios, com até 50.000 habitantes. Concentração que fica mais evidenciada quando analisados aqueles com população de até 20.000 habitantes (categoria de municípios de pequeno porte I), cuja participação supera os $78 \%$.

Por este motivo, considera-se que os repasses do FPM são fonte de grande importância à manutenção das atividades e para o equilíbrio fiscal da maior parte dos municípios de pequeno porte e, conforme discutido em Bremaeker (2011), qualquer alteração em sua distribuição influência de forma importante as finanças municipais.

\subsection{Dependência do FPM - municípios maiores (grupo II)}

Ao analisar os resultados do grupo II, cujos municípios encontram-se na faixa populacional entre 21.641 e 1.475 .517 habitantes, pode-se identificar um comportamento similar aos 100 menores municípios: (i) a participação do Fundo de Participação dos Municípios em relação a receita total reduz conforme a população aumenta e; (ii) a tendência de redução do grau de dependência do FPM foi maior em 2016 comparativamente ao ano de 2009. Além disso, outras duas evidências podem ser destacadas: (iii) a participação média do FPM ficou em 16,77\%, todavia retraiu de 17,75\% em 2009 para 15,79\% em 2016 e; (iv) o intervalo entre os mais e menos dependentes ficou entre $27 \%$ e $3 \%$ (ver Figura 3 ). 
Detalhando, observa-se que o nível de dependência dos menos dependentes ficou entre 3,3\% e 9,3\% em 2009 e entre 3\% e 8,3\% em 2016. Por outro lado, entre os mais dependentes, a dispersão ficou entre $24,3 \%$ e $29,3 \%$ em 2009 e $21 \%$ e 27,5\% em 2016. Estes resultados alinham-se com os encontrados por Santos e Santos (2008), quando explicam que a diferença de arrecadação pode ser explicada pela população municipal, dado que quanto maior o contingente menor a dependência das transferências federais.

Figura 3 - Participação do FPM na receita orçamentária dos 100 maiores municípios do Rio Grande do Sul em 2009 (painel a) e 2016 (painel b), em \%.

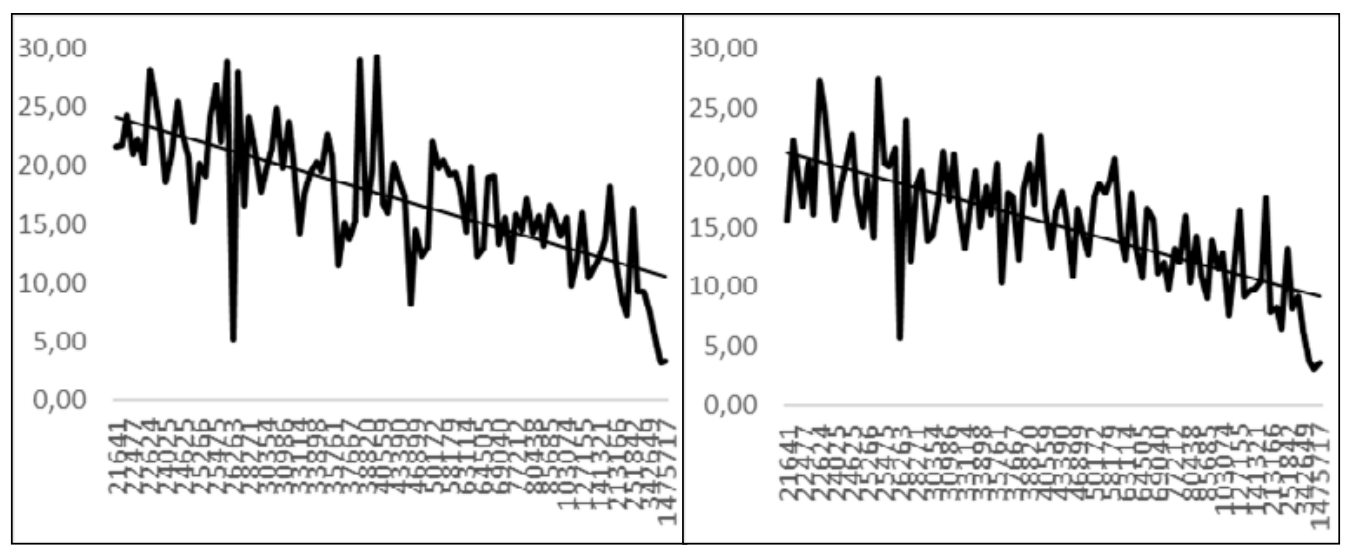

(a)

(b)

Fonte: Elaborado pelos autores.

Os resultados mostraram que em 2009, os municípios de Caxias do Sul, Porto Alegre, Triunfo, Canoas, Novo Hamburgo, Pelotas, Osório, São Leopoldo, Santa Maria e Gravataí foram os dez menos dependentes do FPM. Por sua vez, em 2016, os menos dependentes foram Caxias do Sul, Porto Alegre, Triunfo, Pelotas, Novo Hamburgo, Bento Gonçalves, Rio Grande, Gravataí e São Leopoldo. Ressalta-se que, embora Porto Alegre seja o maior município, com aproximadamente $13 \%$ da população estadual, não apresentou a menor relação FPM/RO nos anos analisados (Figura 4). Ressalta-se que os recursos transferidos às capitais atendem a critério diferenciado dos demais municípios, sejam aqueles denominados de reserva ou de interior quanto aos repasses do FPM.

Entre os mais dependentes, em 2009 encontram-se na figura 4. Observa-se que ocorreu alteração de, praticamente, todos os municípios nos dois períodos analisados, exceto São José do Norte, diferentemente dos municípios menos dependentes que se mantiveram os mesmos nos dois períodos. Esta característica pode estar relacionada a estrutura econômica e fiscal como também associada aos ganhos em termos de renda per capita, condiçáo essa que altera o cômputo dos recursos transferidos. A homogeneidade populacional e os coeficientes discretos de cálculo, critérios técnicos, são outros aspectos que pode explicar esses resultados, porém Mendes (2015) discute que tais critérios provocam distorçóes e limitam a efetividade do mecanismo de equalização das disparidades locais do FPM. 
Figura 4 - Participação do FPM na receita orçamentária dos 10 municípios mais e menos dependentes do Rio Grande do Sul em 2009 (painel a) e 2016 (painel b), em \%.

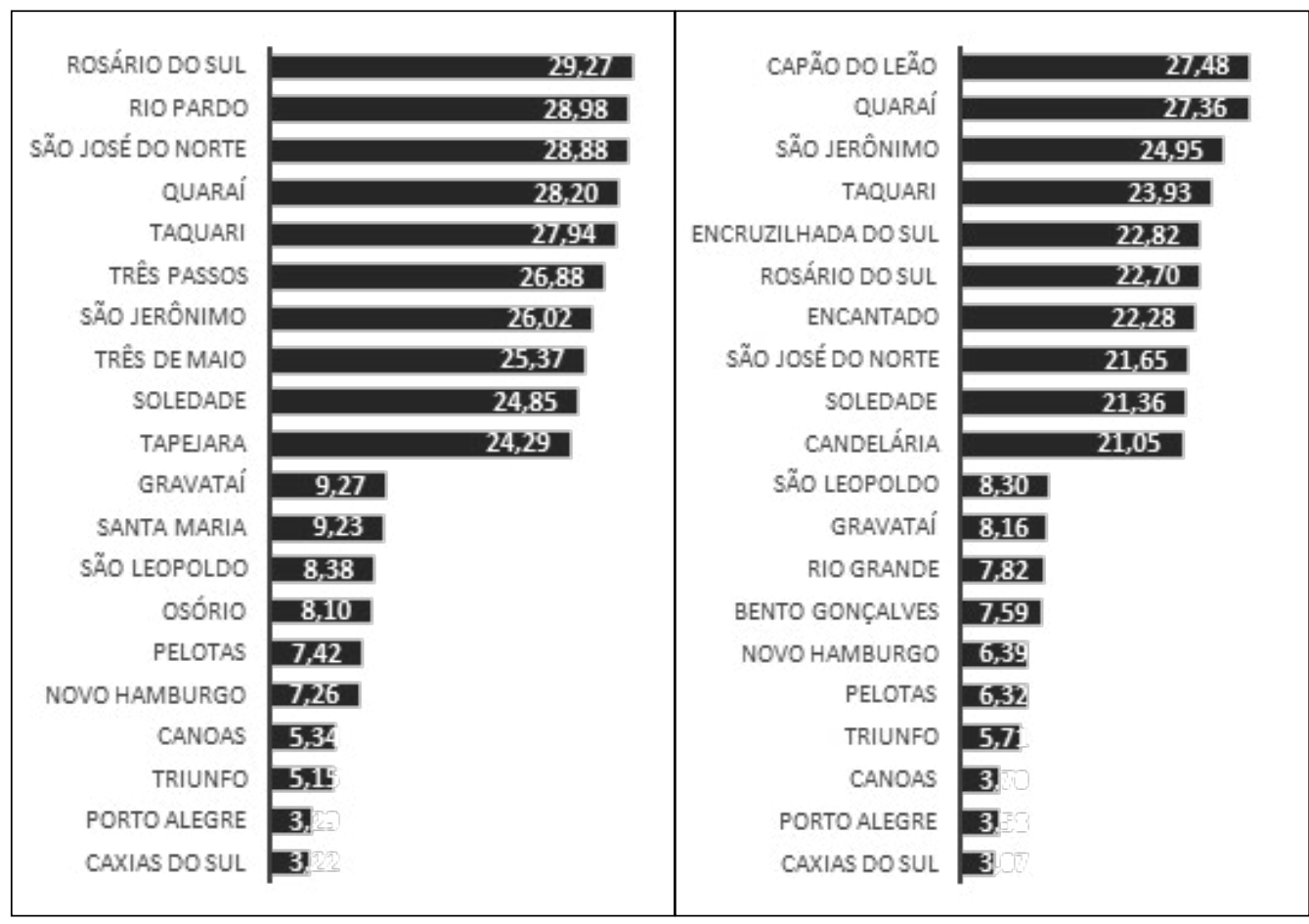

(a)

(b)

Fonte: Elaborado pelos autores.

Já quando relacionado o grau de dependência dos repasses com a faixa populacional, observa-se que em 2009 os menos dependentes estavam entre os dez mais populosos municípios do estado, à exceção de Triunfo e Osório, enquanto que os mais dependentes se encontravam no extrato populacional de 22.000 a 40.000 habitantes. Em 2016, os menos dependentes permaneceram entre os 10 mais populosos, exceto por Triunfo e Bento Gonçalves, enquanto que os mais dependentes se mantiveram no extrato entre $22.000 \mathrm{e}$ 40.000 habitantes, essa relação ressalva novamente a relação populacional e a dependência do FPM, também pode-se levantar questóes sobre qual faixa populacional pode ser considerada mínima para reduzir a dependência do FPM.

\subsubsection{Estrutura arrecadatória e atividade econômica setorial}

Os resultados do nível de dependência dos recursos de transferências são complementados quando relacionados com a estrutura arrecadatória e a atividade econômica dos municípios. Em relação ao grupo dos maiores municípios (grupo II), destacam-se duas evidências: i) peso menor no FPM e ii) aumento do ICMS e outras receitas. Concomitantemente essas duas evidências apontam à influência da população na 
dependência do FPM, que resulta em conclusão: maior a população, menor dependência do FPM.

Tabela 3 - Estrutura fiscal dos dez municípios mais de menos dependentes do FPM, do grupo II, para o ano de 2016

\begin{tabular}{lll}
\hline & \multicolumn{2}{c}{ Receita tributária municipal e seus componentes } \\
\hline & Mais dependentes & Menos dependentes \\
\hline Receita tributária & $\mathbf{1 0} \%$ & $\mathbf{2 0} \%$ \\
ISS & $38 \%$ & $41 \%$ \\
IPTU & $26 \%$ & $22 \%$ \\
ITBI & $10 \%$ & $9 \%$ \\
IRFF & $12 \%$ & $18 \%$ \\
Taxa e contribuiçôes de melhorias & $14 \%$ & $10 \%$ \\
\hline \multicolumn{4}{r}{ Receitas de transferências e seus principais componentes } \\
\hline Transferências & Mais dependentes & Menos dependentes \\
FPM & $\mathbf{7 8 \%}$ & $\mathbf{5 9 \%}$ \\
ICMS & $32 \%$ & $12 \%$ \\
Outros & $27 \%$ & $39 \%$ \\
\hline
\end{tabular}

Fonte: Resultados da pesquisa. Elaborado pelos autores com dados do sistema Meu Município.

Nota-se que os municípios menos dependentes do FPM possuem um percentual maior de suas receitas correntes vinculadas a receita própria, equivalente ao dobro quando comparado aos mais dependentes. Esta discrepância pode ser atribuída ao fato de que estes municípios têm maior nível de atividade econômica e, portanto, maior capacidade de arrecadação de tributos oriundos da renda e da produção de bens e serviços. Concomitantemente, a maior população facilita a tributação sobre o consumo refletida no maior ICMS.

O maior nível de produção nos municípios maiores pode ser explicado, em grande parte, pela diversificação da atividade econômica, produção variada e fortalecida, com importante participação dos setores industrial e de serviços. Resultados que podem ser observados pela distribuição do Valor Adicionado Bruto Total (VAB) entre os setores agropecuário, industrial e de serviços, conforme exposto na Tabela 4.

Tabela 4 - Participação setorial no Valor Adicionado Bruto dos municípios mais e menos dependentes do grupo II, para o ano de 2015, em valores médios.

\begin{tabular}{lll}
\hline & Mais dependentes & Menos dependentes \\
\hline Agropecuária & $19 \%$ & $1 \%$ \\
Indústria & $17 \%$ & $33 \%$ \\
Serviços & $64 \%$ & $66 \%$ \\
PIB em R\$ milhóes & 588 & 15718 \\
\hline
\end{tabular}

Fonte: elaborado pelos autores com dados obtidos da Fundação de Economia e Estatística, 2015. Os dados para o ano de 2016 não estão disponíveis. 
No caso dos dez menos dependentes (Caxias do Sul, Porto Alegre, Triunfo, Canoas, Novo Hamburgo, Santa Maria e Gravataí), a atividade econômica está concentrada em setores de alto valor agregado. Para estes, em média, o setor industrial representa $33 \%$ do Valor Adicionado Bruto (VAB); por outro lado, os dez mais dependentes de transferências constitucionais do FPM possuem atividade econômica menos industrializada, com este setor representando $17 \%$ do $\mathrm{VAB}$ total.

Logo, constata-se que economias menos industrializadas encontram maiores dificuldades para gerar renda e, consequentemente, receita tributária. Os dez municípios mais dependentes do grupo II apresentaram VAB de $19 \%$ e $64 \%$ para os setores de agropecuária e serviços, respectivamente; em contraposição, os valores médios foram de $1 \%$ e $66 \%$ para os municípios menos dependentes. Essa discrepância se reflete no valor do produto agregado final, os menos dependentes possuem um PIB em média 26 vezes maior que os mais dependentes, a diferença equivalente a $\mathrm{R} \$ 151.530,00$ milhóes, em média.

Estes resultados refletem também a faixa populacional dos municípios, cuja população varia entre 21.641 e 1.475 .717 habitantes, sendo que os dez mais dependentes têm média de 28.000 e os menos dependentes média de 373.000 habitantes (se desconsiderar Porto Alegre, a média desse último grupo cai para cerca de 248.000 habitantes). Ressalta-se que, dos 100 maiores municípios do estado, $57 \%$ deles tem até 50.000 habitantes, enquanto que apenas $20 \%$ tem população superior a 100.000 habitantes, essas características apontam para maior produto, maior diversificação da produção, maior arrecadaçáo e menor dependência.

\section{Conclusóes}

O equilíbrio fiscal dos municípios ainda se encontra entre os temas pouco debatidos sobre finanças públicas, todavia as restrições orçamentárias têm se agravado com as sucessivas crises econômicas e fiscais, de forma que esses entes têm sido duplamente afetados, seja pela redução das receitas próprias quanto pelo menor volume de recursos transferidos. Esta conjuntura tem impactado expressivamente na capacidade arrecadatória dos municípios e, por sua vez, nas condiçôes de ofertarem adequadamente os serviços públicos prioritários.

A partir destas condiçóes, compreender a dinâmica fiscal dos municípios, principalmente no que tange as transferências constitucionais, caso do Fundo de Participação dos Municípios, que se constitui na principal fonte de recursos de grande parte desses entes públicos, torna-se relevante à discussão fiscal e das condiçōes estruturais dos municípios. Pautado nestes pontos, avaliou-se o nível de dependência dos 100 maiores e dos 100 menores municípios do Rio Grande do Sul em relação às transferências do FPM.

Os resultados permitiram observar uma relação inversamente proporcional entre a população e a dependência dos repasses do governo. Quanto maior a população, menor a dependência do FPM e quanto menor a populaçáo, maior a dependência desses recursos. Os menores municípios apresentaram nível médio de dependência de $46,31 \%$, enquanto que o percentual encontrado para os maiores municípios foi de 15,19\%. Dentro do grupo dos maiores municípios foram analisados os dez mais e menos dependentes, que apresentaram níveis de dependência de $23,56 \%$ e $6,06 \%$, respectivamente. A mesma comparação foi 
realizada para o grupo dos menores municípios, sendo encontrados percentuais de 57,35\% e 34,76\% para os dez mais e menos dependentes, respectivamente.

Os municípios maiores têm reduzida dependência dos repasses da União pois suas arrecadaçóes próprias apresentam participação mais expressiva na arrecadação total, não ocorrendo o mesmo com os municípios menores, cuja capacidade de arrecadar tributos próprios é baixa, fazendo-se necessário recursos de outros entes. Além disso, os anos analisados demonstraram que, em 2016 o nível dependência dos repasses governamentais diminuiu, o que pode ser resultado de duas situaçóes: (i) os efeitos da crise fiscal impactaram mais do que instabilidades externas sobre as finanças municipais e; (ii) a queda no volume de repasses do FPM foi maior comparada a retração arrecadação tributária municipal, não refletindo necessariamente melhoria em termos de dependência dos repasses constitucionais.

Estes resultados são complementados pela relação entre a estrutura econômica municipal e a capacidade de arrecadaçáo, a qual demonstrou uma clara divisão, com os municípios mais dependentes, de ambos os grupos, apresentado o setor agrícola com principal gerador de renda, enquanto que os menos dependentes tem no setor industrial a base da formação de renda e da tributação. Também há indícios de uma correlação positiva entre maior arrecadação e o tamanho da população

Também, os resultados ratificam que a elevada heterogeneidade demográfica e estrutural entre os municípios tem ampliado as crescentes disparidades sociais e econômicas, característica que torna cada vez mais necessário um sistema de equalização das disparidades regionais, como também a rediscussão da estrutura de repartição dos recursos federativos. Isso evidencia-se quando os maiores municípios gaúchos, que são menos dependentes, contribuem com o produto agregado de forma discrepante entre os municípios da própria categoria, os quais que são mais dependentes de recursos de repasses.

Embora os resultados tenham demonstrado, ainda que preliminarmente, a estrutura fiscal dos municípios do estado do Rio Grande do Sul quanto ao seu nível de dependência de repasses governamentais, destaca-se a importância de novos estudos acerca das transferências constitucionais como também dos demais repasses públicos para o equilíbrio fiscal dos municípios e seus resultados para o crescimento econômico, como forma de subsidiar a discussão acerca do modelo arrecadatório vigente.

\section{Referências}

BAIÃO, Alexandre. Lima. O papel das transferências intergovernamentais na equalização fiscal dos municípios brasileiros. Rio de Janeiro: Escola Brasileira de Administração Pública e de Empresas, Fundação Getúlio Vargas - FGV, 2013. 70 p. Dissertação apresentada à Escola Brasileira de Administração Pública e de Empresas.

BRASIL. Constituição (1988). Constituição da República Federativa do Brasil. Brasília, DF: Senado, 1988.

Emenda Constitucional no ${ }^{\circ}$ 18, de $1^{\circ}$ de dezembro de 1965. Brasília, DF:

Senado, 1965. Recuperado em 27 junho, 2017, de www6.senado.gov.br/legislação. 
BRASIL. Finanças: procedimento para otimizar a arrecadação municipal. Confederação Nacional de Municípios (CNM). Brasília: CNM, 2012.

BREMAEKER, F. E. J. Reforma Tributária: Vantagem ou Desvantagem para os Municípios. Transparência Municipal. Salvador, 2011. Disponível em: <http://www. oim.tmunicipal.org.br/abre_documento.cfm?arquivo=_repositorio/_oim/_documentos/ E2197D39-D92A-AA47-A921B9958CD4ACCE03102011094320.pdf\&i=1543 > Acesso em: 01 abr 2018.

BRITO, H. S.; DIAS, R. R. O Comportamento da Receita Pública Municipal: Um Estudo de Caso no Município de Parnaíba - PI. Revista de Gestáo e Contabilidade da UFPI, [S.l.], v. 3, n. 1, p. p.130-146, dez. 2015. ISSN 2358-1735. Disponível em: <http://www.ojs.ufpi.br/index.php/gecont/article/view/3466>. Acesso em: 15 mar. 2018.

COSSIO. F. A. B; Ensaios sobre Federalismo Fiscal no Brasil. Dissertação (Doutorado Economia). Pontifício Universidade Católico do Rio de Janeiro. 2002.

COSTA E CASTELAR. O Impacto das Transferências Constitucionais sobre os Gastos dos Municípios Brasileiros. Revista Análise Econômica. v. 33, n. 64. Set. 2015

IBGE. Censo demográfico 2010. Recuperado em 27 junho, 2017, de http://www. ibge.gov.br/home/estatistica/populacao/censo2010/caracteristicas_da_populacao/ caracteristicas_da_populacao_tab_pdf.shtm

\section{FEDERAÇÃO DAS ASSOCIAÇÕES DE MUNICÍPIOS DO RIO GRANDE DO}

SUL- FAMURS. Turno único é adotado em pelo menos 121 prefeituras gaúchas. Disponível em: http:/www.famurs.com.br/noticias/turno-unico-e-adotado-em-pelomenos-121-prefeituras-gauchas (2016) Acessado em 15. dez. 2016.

\section{FEDERAÇÃO DAS ASSOCIAÇÓES DE MUNICÍPIOS DO RIO GRANDE DO}

SUL- FAMURS. Turno único é adotado em pelo menos 121 prefeituras gaúchas.

Disponível em: http:/ http://www.famurs.com.br/notas_tecnicas/impacto-da-queda-dofpm-e-icms-nos-municipios-gauchos-2015/ (2016) Acessado em 15. dez. 2016.

GIROLDO. C. N; KEMPFER. M. Autonomia municipal e o federalismo fiscal brasileiro. Revista de Direito Público, Londrina, V. 7, N. 3, P. 3-20, set./dez. 2012.

MATIAS-PEREIRA, Jose. (2012). Manual de gestáo pública contemporânea. 4. ed. São Paulo: Atlas.

MARQUES JÚNIOR. L. dos S; OLIVEIRA; C. A. de O.; LAGEMMAN E., 2012 FEDERALISMO FISCAL BRASILEIRO: PROBLEMAS, DILEMAS E AS COMPETÊNCIAS TRIBUTÁRIAS. Revista da Associaçáo Mineira de Direito e Economia. Minas Gerais, Ano 2013 v. 9. 
MASSARDI, W.de.O; ABRANTES, L.A.: DEPENDÊNCIA DOS MUNICÍPIOS DE MINAS GERAIS EM RELAÇÃO AO FPM. Revista de Gestáo, Finanças e

Contabilidade, ISSN 2238-5320, UNEB, Salvador, v. 6, n. 1, p. 173-187, jan./abr., 2016.

MENDES, C. C. Critérios atuais de repartição dos recursos do FPM. Câmara dos

Deputados Comissáo Especial - Pacto Federativo. DIRUR/IPEA, set. 2015.

PORTAL MEU MUNICÍPIO. Recuperado em 12 de agosto, 2018, disponível em <https://meumunicipio.org.br/>.

OLIVEIRA, C. A. de; LAGEMANN, E.: A política fiscal como um jogo entre união, estados e municípios no federalismo fiscal brasileiro. Economic Analysis of Law Review, v. 3, p. 223-245, 2012.

PINHAL DA SERRA. Economia. Recuperado em 09 outubro, 2019 de <http://www. pinhaldaserra.rs.gov.br/economia>.

PRADO, S. Introdução conceitual e visão geral do sistema. In: PRADO, Sérgio (Org.). Transferências Intergovernamentais a Federação Brasileira: avaliação e alternativas de reforma. Rio de Janeiro: Fórum Fiscal dos Estados Brasileiros, Caderno n. 6, v. 2, 2007.

RECEITA FEDERAL DO BRASIL. Instruçáo Normativa n. 643 , de 12 de abril de 2006. Acesso em Agosto 2018, Disponível em: <http://normas.receita.fazenda.gov.br/ sijut 2 consulta/link.action?idAto $=15581 \&$ visao=compilado. $>$

REZENDE, Fernando. Os Desafios do Federalismo Fiscal. In: REZENDE, F.. (Org.). Desafios do Federalismo Fiscal. Rio de Janeiro: FGV Editora, 2006.

RIBEIRO, M. B.: Uma resenha sobre as avaliaçóes mais recentes dos efeitos locais das transferências do fundo de participação dos municípios (FPM). Boletim regional, urbano e ambiental IPEA, jul/dez 2016.

SANTOS, K. G. B. dos; SANTOS, C. E. R.: Dependência municipal das transferências do fundo de participação dos municípios: uma análise para os municípios do Sul da Bahia entre 2008 e 2012. Anais...IV Semana do Economista, out. 2014, UESC, BA.

THEÓPHILO, C. R.; TOLENTINO, M. A.; SANTOS, M. G. dos; SILVA, S. P. da.: Gestão empreendedora de recursos públicos: receita tributária em face do FPM no município de Salinas, Norte de Minas Gerais. Revista mineira de contabilidade, Conselho Regional de Contabilidade de Minas Gerais, Belo Horizonte, Ano 12, no 42, p. 6-13, abr./mai./jun. 2011

TESOURO NACIONAL. Transferências constitucionais. Recuperado em 09 agosto, 2017, de <http://sisweb.tesouro.gov.br/apex/f?p=2600:1>.

TRIBUNAL DE CONTAS DO ESTADO DO RIO GRANDE DO SUL. Recuperado em 27 junho, 2017, de http://www1.tce.rs.gov.br/portal/page/portal/tcers/ 